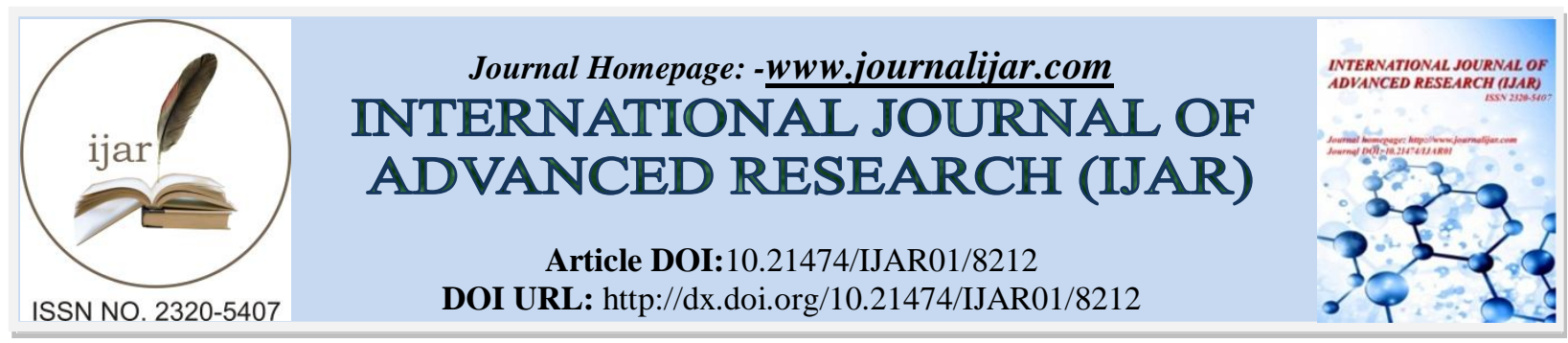

RESEARCH ARTICLE

\title{
MAINTAINING GURAGINA LANGUAGE WITH REFERENCE TO STATUS AND ATTITUDE
}

Chernet Zerga Wejira and Dr. Tiglu Geza Nisrane

College of Social Science and Humanities, Department of English Language and Literature, Wolite University

\section{Manuscript Info}

\section{Manuscript History}

Received: 16 October 2018

Final Accepted: 18 November 2018

Published: December 2018

Keywords:

Guragina, Gurage people, language attitude, language status, language shift and mother tongue education.

\begin{abstract}
This paper describes a research project that examines maintaining Guragina language with reference to attitude and status of the language in the community in Gurage Zone, Ethiopia. A total of 340 questionnaires distributed to the speakers of Guragigna in the Zone. Twenty four key informants were interviewed for their opinions on the use and importance of Guragina. Besides, 6 FGDs were conducted. The findings show that participants' attitude towards the language is positive. They also agreed that Guragigna is multifarious in dialect, with some in the community viewing it as a language of solidarity, while others bemoan its irrelevance in the changed circumstances of modern life. The finding also suggests that the respondents are not satisfied with their current ability to speak the language; they make language shift to the use of Amharic. Furthermore, Guragina is a low status language with low social and economic prestige and poor documentation. Guragina is mainly used at home and market domains. Instead Amharic is the dominant language in the court, office and religious places with some shift from Amharic to Guragina and viceversa.Thus all levels of government should support the profile and prestige of Guragina language by allowing it to be used in a range of public functions such as legal situation, health situations. Besides the local and regional government should introduce Guragina language as a subject to be taught in schools using comparative analysis of Guragina language varieties, and in long term the language should be used as medium of instruction by standardizing Guraginavarities. Besides,Guragina language centre should be opened at Wolkite University for studying the language and documentation.
\end{abstract}

Copy Right, IJAR, 2018,. All rights reserved.

\section{Introduction}

Language is a cultural resource to be used to fit the goals of various ethno-linguistic groups of a society. It determines how people are related one to another within a society. According to Fasold (1984:46) and Fishman (2006:10), people interpret the identity of their interlocutors based on very delicate features of behavior, among which language is particularly central. It builds human societies, solidarity and cooperation, and plays a crucial role in the distribution of power and resources within a community and among communities (Baye 2012:39; Wright 
2004:5). At the same time, language can be employed to include as well as exclude the participation of a community in political and social activities.

It is believed that the development of a community is inseparable from the promotion on its language. For example, Robinson (1996:4) states that development can be attained when people get access to education through their local language. It is difficult to achieve the development of a skillful and knowledgeable community unless the people have information in the language they know well.It is believed that people develop self-respect and actively participate in social, political and economic processes when they use their language.

As a multilingual nation, in Ethiopia several languages coexist; in the process people develop the tendency to use one language more frequently than the other. The status and importance of a language in society and within an individual obtains largely from adopted attitudes. Usually, for monolingual speakers, they have only one attitude towards their language because there are no other languages which can be made comparison. They value the language positively as they see their language as a central means for communication, socialization and ethnic identity. The attitudes will normally depend on the degree of symbolic or socio-economic value manifested by each language.

The language maintenance is thus not merely depending on the type of attitudes, but also on the status and regular use of the language. Besides, attitudes in language is crucial in determining the extent of current usages of a language, the prospect of extension, and the kinds of prestigious contexts in which it will be used or denied use (Lewis, 1981).

\section{Statement of the Problem}

Ethiopia is endowed with diversified ethnic groups with their own languages. In the past, Amharic and foreign languages were given a high prestige. As a result, most people had a low esteem for other local languages. Recently, however, the constitution and the language-in education policy of Ethiopia encourage the use of local languages.

However, in Gurage Zone dominant languages, Amharic and English are used in Education instead of local language, Guragigna. The local people were urged to give high prestige for Amharic and foreign languages, but low esteem to their own local language.

For this reason, there are still challenges in Gurage language use, attitudes and development decisions in the zone.The constitution expresses all languages have equal status but the government of the zone encourages the use of other languages as the only working or official language, a language of education and media. The low status of Guragigna language is clearly reflected in the discrepancy between government spending on other Ethiopian languages and on this language. This leads to unfair contest among the languages that leads the decline of Gurage language use.

Guragigna is not used widely for communication within the community and at government offices. There are also constraints in the use of the language in the media as well. Lack of terminology development had serious implications for using the language. Linguistic diversity within Gurage posed another challenge in the use of the languages as MOI in schools. Standard Guragigna is not developed based on any of the actually occurring dialects. This study thus deals with the attitude of its people towards language use and its status in the overall participation of the community in educational, economic, social, political and cultural development. Therefore, the question is, do Gurage people have negative attitude towards the use of their language for education, media and official purpose in the zone?

This study is required to identify the gaps between the language attitudes and the actual practice of language use and status in the community. In our observations in Gurage zone, there are dissatisfactions put across by the people in the use and the development of their language to achieve the intended status and standardization. In the Zone, it is clearly observed that there is contest in languages use. It is crucial to recognize language tribulations in the community and find out contextual solutions based on the actual practice of the language use in the community. The status and importance of a language in society and within an individual obtains largely from learnt attitudes.

Therefore, the study seeks to investigate language attitudes of Gurage people towards their own language, the language used in different domains and constraints to maintain Guragigna as an indigenous language. 


\section{Objectives of the Study General Objective of the Study}

The overall objective of this study is to investigate the practices of maintainingGuragiga language with reference to attitude and status of the language in the community.

\section{Specific Objectives of the Study}

Specifically, the objectives of this study are to:

1. Investigate the attitudes Gurage people possess towards Guragigna language.

2. Identify the use of Guragigna Language in family, market, friendship, religion and employment domains.

3. Find out the status of Guragigna language for various functions.

4. Assess the feasibility of incorporating Guragigna as a subject at the elementary education curriculum.

\section{Significance of the Study}

This study is conducted due to the seemingly rapid decline of Guragigna language use. Therefore, findings from this study is hoped to create awareness at the community level towards the decline in usage of the language, as an initial representation of community's view towards Guragigna language. It could also be pertinent information for language planning efforts by the government and other bodies of Gurage people and their culture to promote and maintain the Guragigna language.

\section{Scope of the study}

The focus of this study is on the attitudes of the community towards their language. Apart from that, in the analysis of language status of respondents, the focus is on their ability on the use of Guragina. Thus the study limited to collect information on the six selected woreda based on their dialect variation.

\section{Methodology:-}

\section{Research Design}

This study employed a mixed approach in assessing the attitude and status of Guragigna language. Survey method was used to measure the attitude, language use and language status of the participants. Qualitative methods were also used to triangulate the data collected through quantitative methods. The study provides a detailed description of language attitudes and practices in the Zone and also offers an interpretation why these language attitudes and practices are employed and how the community perceived the current status of the language.

The data was collected in face-to-face interview and through a written questionnaire distributed to stakeholders (teachers, administrators, students and parents). Furthermore, observation and FGD were used to collect data.

\section{Sampling and Participants of the Study}

The target population for this study lives in Gurage Zone. The zone has 14 Weredas and two town administrations. Six Weredas and some selected offices in town administrations were chosen by using purposive sampling. Availability sampling was employed to identify the status of the language in market domain. The dialect variation was taken into consideration during the selection of the Weredas in order to come up with diversified responses on language use in the zone.

A total of 340 participants were selected using stratified sampling. The data were collected from respondents (teachers, students, community elders, parents and governmental workers randomly selected from the six Weredas (Sodo, Meskan, Muher, Cheha, Enemore and Geta).

The reason for including parents in the study is home and parents are often the last important agent in preservation of any language (Antonini, 2002). Parent is model for children language learning and influence the likelihood of what language will the children adopt and learn (Bartram, 2006; Galindo \& Worthy, 2006). The researchers selected elementary school students and teachers to collect data about their attitude to attend their education and teach in their mother tongue respectively. Similarly, teachers and students attitude about incorporating Garaging as a subject into the curriculum of elementary education is assessed, for they are the ones to be affected if the program is implemented.

Similarly, whether the participants use their mother tongue in different domains of communication was assessed. To collect data on attitude, status and transmission of Guragigna across generation, the researcher believes that pertinent data were obtained from community elders. 
Apart from measuring their attitudes, government officials and experts from cultural and educational offices were included in the study as source of data in assessing the status of the language and the practical challenges faced in maintenance of the language.

\section{Data Collection Instruments Questionnaire}

In order to gain a better understanding of the participants' thoughts about their indigenous language, language use as well as their language background a questionnaire on Indigenous Languages Survey (ILS) was adapted and distributed to 340 participants that included teachers, students, administrators and office workers. The questionnaire has four sections: section one demographic information, section two the participants' thoughts about their indigenous language and section three language use. The questionnaire embraced close ended questions to obtain adequate information from the participants.

\section{Interview}

Twenty four key informant interviews were conducted. Four participants from each selected Weredas were purposively selected. The researcher uses semi-structured interview in an effort to draw out research participants' attitude on Guragigna language revitalization.

\section{Focus group discussion}

Six focus group discussions were conducted. Within the focus group discussions, twelve participants were purposively selected from teachers, students, administrators and office workers and parents). Key questions were set based on the specific objective of the study. This would help to triangulate the data obtained.

\section{Procedure}

Participants were asked to fill in an anonymous language survey in Amharic which began with an attitudinal item asking how much they would have preferred the questionnaire to be in their indigenous language if they were as fluent in that language as they were in Amharic. Other items on the questionnaire assessed language use, attitudes about language use in various public and private contexts and current status of the language. Participants were asked about the degree to which they mixed Amharic and their mother tongue in communication. In addition, participants were asked to provide other information (e.g. age, gender, etc). Participants would respond to most items on 5 point Likert scales and some as 'Yes' or 'No'.

\section{Pilot Study}

Pilot study was conducted to verify whether the questions in the questionnaires, interviews and FGD guides capture the intended information, and to check if the language is clear enough for the respondents to interpret the questions properly. It was checked whether there is any bias provoking distrust from the side of the respondents. This would help to check the effectiveness of the questionnaire and methods. The pilot study was conducted in Enemore and GumerWeredas using sixty participants randomly selected.

\section{Methods of data Analysis}

Data collected through questionnaire was tabulated and analyzed using frequency and percentage. Statistical Package for Social Science (SPSS) software was used for analysis. Data collected through interview and focus group discussion were analyzed qualitatively.

\section{Findings and Discussion}

In order to achieve the objectives of the study in the first chapter of this study, necessary data were gathered using three methods: questionnaire, interview and Focus Group Discussion. The data collected were analyzed using frequency and percentage. In the next sections, the data gathered through each method are treated separately and interpretations are made with the intention to reach possible conclusions that can lead to workable recommendations. In this study, four specific objectives were explained regarding maintaining Guragina language with reference to attitude and status of the language in the community. Five of the items in questionnaires were incomplete and they were discarded. Thus three-hundred and fourteen of the items in the questionnaire were ready for analysis. The results are presented in the same order with the specific objectives produced for the study.

\section{Findings of Questionnaire Participants Attitude towards Guragina Language Maintenance}

Table 1:-Participants Attitude towards Guragina Language Maintenance 


\begin{tabular}{|l|l|l|l|l|l|l|l|}
\hline s.n & Item & \multicolumn{2}{l|}{ Yes } & \multicolumn{2}{l|}{ Uncertain } \\
\cline { 3 - 7 } & & $\mathrm{F}$ & $\%$ & $\mathrm{~F}$ & $\%$ & $\mathrm{~F}$ \\
\hline 1 & $\begin{array}{l}\text { All members value their language and wish } \\
\text { to see it promoted. }\end{array}$ & 320 & 94.1 & 0 & - & 20 & 5.9 \\
\hline 2. & $\begin{array}{l}\text { Most members support language } \\
\text { maintenance. }\end{array}$ & 270 & 79.4 & 30 & 8.8 & 40 & 11.8 \\
\hline 3 & $\begin{array}{l}\text { Only a few members support language } \\
\text { maintenance; }\end{array}$ & 40 & 11.8 & 250 & 73.5 & 50 & 14.7 \\
\hline 4 & $\begin{array}{l}\text { Some members supports language shift (eg. } \\
\text { to Amharic) }\end{array}$ & 90 & 26.5 & 140 & 41.2 & 110 & 32.4 \\
\hline 5 & $\begin{array}{l}\text { No one cares if the language is given up; all } \\
\text { prefer to use a dominant language. }\end{array}$ & 100 & 29.4 & 210 & 61.8 & 30 & 8.8 \\
\hline
\end{tabular}

As can be seen in the table above the majority (94\%) of the respondents indicated that all members of the community value their language and wish to see it promoted, and only $5.9 \%$ of them reported that they are uncertain. With regards to attitude to language maintenance in item 2 above the majority (79.4\%) of respondents reported that most members support language maintenance whereas few $(8.8 \%)$ of them said No and $11.8 \%$ of them Uncertain. Similarly $73.5 \%$ of the respondents replied No to the third item that says only a few members support language maintenance, and $11.8 \%$ of them replied Yes. The finding of item-1 is consistent with that of item-3 which indicates Gurage people value their language and want to see it promoted.

Concerning language shift in item-4 significant number of respondents (41.2\%) said No, where as $26.5 \%$ of them replied Yes and 32.4\% of them were Uncertain. Likewise most (61.8\%) of the respondents said No to item-5 that goes No one cares if the language is given up; all prefer to use a dominant language, and $29.4 \%$ of them replied Yes to prefer a dominant language. The fact that some $(29.4 \%)$ of the respondents said nobody cares if the language is given up and prefer a dominant language such as Amharic seems due to the fact that they use Amharic, not Guragina, in social and economic aspect of their lives. what has been reported so far it can be inferred that the respondents value Guragina language and would like to see it developed and maintained, but Amharic dominance seem to influence some of them to prefer language shift.

\section{Participants Attitude towards Guragina Language Use}


Table 2:-Participants Attitude towards Guragina Language Use

\begin{tabular}{|c|c|c|c|c|c|c|c|c|c|c|c|}
\hline \multirow[t]{2}{*}{ S.n } & \multirow[t]{2}{*}{ Item } & \multicolumn{2}{|c|}{$\begin{array}{l}\text { Strongly } \\
\text { Disagree }\end{array}$} & \multicolumn{2}{|c|}{ Disagree } & \multicolumn{2}{|c|}{ Uncertain } & \multicolumn{2}{|c|}{ Agree } & \multicolumn{2}{|c|}{$\begin{array}{l}\text { Strongly } \\
\text { Agree }\end{array}$} \\
\hline & & $\mathbf{F}$ & $\%$ & $\mathbf{F}$ & $\%$ & $\mathbf{F}$ & $\%$ & $\mathbf{F}$ & $\%$ & $\mathbf{F}$ & $\%$ \\
\hline 6 & Gurage culture can survive without Guragina & 80 & 23.5 & 230 & 67.6 & 0 & 0 & 20 & 5.9 & 10 & 2.9 \\
\hline 7 & $\begin{array}{l}\text { It is important for Guragina speakers to pass } \\
\text { their language knowledge to future } \\
\text { generations }\end{array}$ & 0 & 0 & 5 & 1.45 & 5 & 1.45 & 70 & 20.6 & 260 & 76.5 \\
\hline 8 & $\begin{array}{l}\text { The use of Guragina is a strong part of my } \\
\text { identity. }\end{array}$ & 4 & 1.45 & 16 & 3.9 & 10 & 2.9 & 60 & 17.6 & 250 & 73.5 \\
\hline 9 & $\begin{array}{l}\text { There is too much support for Guragina } \\
\text { language }\end{array}$ & & & 110 & 32.4 & 50 & 14.7 & 100 & 29.4 & 80 & 23.5 \\
\hline 10 & The use of Guragina helps its people & 0 & 0 & 20 & 5.9 & 50 & 14.7 & 140 & 41.2 & 130 & 38.2 \\
\hline 11 & $\begin{array}{l}\text { It is more important to be able to speak } \\
\text { Guragina than Amharic. }\end{array}$ & 70 & 20.6 & 120 & 35.3 & 50 & 14.7 & 60 & 17.6 & 40 & 11.8 \\
\hline 12 & $\begin{array}{l}\text { The use of Guragina improves my } \\
\text { wellbeing. }\end{array}$ & 120 & 35.3 & 120 & 35.3 & 30 & 8.8 & 30 & 8.8 & 40 & 11.8 \\
\hline 13 & $\begin{array}{l}\text { I feel that most people in my community are } \\
\text { not interested in keeping Guragina strong }\end{array}$ & 20 & 5.9 & 10 & 2.9 & 0 & 0 & 70 & 20.6 & 240 & 70.6 \\
\hline 14 & $\begin{array}{l}\text { I would like to be able to help other people } \\
\text { learn it. }\end{array}$ & 20 & 5.9 & & & 20 & 5.9 & 100 & 29.4 & 200 & 58.8 \\
\hline 15 & $\begin{array}{l}\text { I am satisfied with my current ability to } \\
\text { speak }\end{array}$ & 20 & 5.9 & 60 & 17.6 & 20 & 5.9 & 130 & 38.2 & 110 & 32.4 \\
\hline 16 & $\begin{array}{l}\text { It is important to me that my children learn } \\
\text { and use Guragina }\end{array}$ & 20 & 5.9 & & & & & 100 & 29.4 & 220 & 64.7 \\
\hline
\end{tabular}

The second part of the questionnaire contains items for assessing the participants' attitude towards Guragina language use. The findings of this part of the questionnaire are indicated below.

The sixth item in the table above is designed to find out whether Gurage culture can survive without Guragina. While $67.6 \%$ of the respondents disagreed and 23.5\% Strongly Disagreed, 5.9\% and 2.9\% Agreed and Strongly Agreed respectively to this item. The majority (Strongly Disagreed and Disagreed combined, 93.1\%) of the respondents believe in the fact that culture and language are inseparable.

With regards to the importance of passing the Knowledge of Guragina language to the next generation, while only $1.45 \%$ of the informants disclosed their disagreement to this item. $97.1 \%$ (both Strongly Agreed and Agreed) of the respondents reported that it should be kept and passed to the next generation. This is consistent with the finding in item six above which implies the fact that the respondents' culture could be kept to the next generation if their language is survived.

The seventh item is designed to find out whether the use of Guragina is a strong part of identity. 91.1\% (Strongly Agreed and Agreed) of the participants disclosed their agreement to this item. This finding supports the one in item6 where the majority of respondents agreed that their culture cannot survive without Guragina which implies that they believe Guragina to be their identity.

In the tenth item which intends to point out if the use of Guragina helps its people, $38.2 \%$ and $41.2 \%$ of them responded Strongly Agree and Agree respectively. Whereas $5.9 \%$ of the informants said Disagre, $14.7 \%$ of them reported Uncertain to this item. The majority (79.4\%) of the participants reported their agreement to this item indicates they believe Guragina is helpful to its speakers.

The findings so far show that the respondents have positive attitude towards their language. According to Richards et al. (1985), positive attitude towards a language may reflect degree of importance a language has. This degree of importance that the informants believe Guragina has could be because it helps them build culture and identity.

The eleventh item is devised to find out whether it is more important to be able to speak Guragina than Amharic. While $20.6 \%$ replied Strongly Disagreed and 35.3\% of them Disagreed, $11.8 \%$ and $17.6 \%$ of them reported 
Strongly Agreed and Agreed respectively. Based on the data the majority of respondents favored speaking Amharic (55.9\%, Strongly Disagreed and Disagreed together) than Guragina (29.4\% Strongly Agreed and Agreed together).

The respondents assume more importance to Amharic than Guragina due to better social and economic status it has. The twelfth item is meant to figure out whether the use of Guragina improves the respondents' wellbeing. As can be noted in the table above, while 35.3\% and 35.3\% of the respondents replied Strongly Disagree and Disagree respectively, $11.8 \%$ and $8.8 \%$ of them said Strongly Agree and Agree respectively. A great deal of $(75.6 \%)$ respondents said Guragina does not improve their wellbeing. This is similar with the finding of item eleven where the respondents gave more importance to speaking Amharic than Guragina.

This finding implies that even though the participants showed a positive attitude towards Guragina for its symbolic value (culture and identity), for example as in items- 6 and 8 above, they also gave positive attitude to Amharic due to its socio-economic prestige. The more prestigious a language, the more positive the speaker' attitude towards the language, and the less prestigious a language, the more negative the attitudes are (Batibo, 2005).

Item thirteen is designed with the view to point out if most people in the respondents' community are not interested in keeping Guragina strong. With regard to the responses given to this item, $70.6 \%$ of the respondents replied Strongly Agree and 20.6\% of themAgree whereas 5.9\% and $2.9 \%$ replied Strongly Disagree and Disagree respectively.

A great deal of $(91.2 \%)$ of the respondents indicated that Guragina is not getting the required attention and care to make it strong.

With regard to item fourteen, 58.8\%and 29.4\% of the respondents replied that they Strongly Agreed and Agreed respectively that they would like to be able to help other people learn Guragina. This indicates the respondents' positive attitude to the language.

The fifteenth item is concerned with the respondents' current ability to speak Guragina. The majority (67.6\%) of the respondents reported that they are not satisfied with their current ability to speak the language. Only $23.5 \%$ of the respondents reported that they are satisfied with their ability to speak in Guragina.

\section{This finding shows that there is language shift to the use of Amharic}

The last item in this part of the questionnaire is devised to identify whether it is important to the respondents and their children to learn and use Guragina. $64.7 \%$ and $29.4 \%$ of the respondents reported Strongly Agree and Agree respectivelyabout the importance oflearning and using Guragina.

This finding is consistent with the finding of item-14 about importance of learning the language that indicates the participants' positive attitude to the language.

Generally, the items included in part-two of the questionnaire are mainly related to respondents attitude to support its maintenance; whether they believe Guragina helps them build their culture and identity. The data obtained showed that the participants have positive attitude to Guragina. It can be inferred that Gurage people have a positive attitude towards Guragina for its symbolic value (culture and identity). However, the participants indicated their dissatisfaction with regards to the role of Guragina in building social and economic prestige of Gurage people.

Guragina Language Use in Different Domains

Table 3:-Guragina Language Use in Different Domain

\begin{tabular}{|l|l|l|l|l|l|l|l|}
\hline S.n & Item & \multicolumn{2}{l|}{ Guragina } & \multicolumn{2}{l|}{ Amharic } & \multicolumn{2}{l|}{ Amharic\&Guragina } \\
\cline { 4 - 9 } & & F & $\%$ & F & $\%$ & F & $\%$ \\
\hline 17 & $\begin{array}{l}\text { What language is most commonly } \\
\text { used for oral communication in } \\
\text { community? }\end{array}$ & 30 & 8.8 & 170 & 50 & 140 & 41.2 \\
\hline 18 & $\begin{array}{l}\text { What language is commonly used } \\
\text { for writing? }\end{array}$ & 0 & 0 & 340 & 100 & 0 & 0 \\
\hline 19 & What language is used for & - & - & 340 & 100 & - & - \\
\hline
\end{tabular}




\begin{tabular}{|l|l|l|l|l|l|l|l|}
\hline & reading? & & & & & & \\
\hline 20 & $\begin{array}{l}\text { What language do you use in the } \\
\text { court? }\end{array}$ & 0 & 0 & 320 & 94.1 & 20 & 5.9 \\
\hline 21 & $\begin{array}{l}\text { What language do you use at } \\
\text { health sectors? }\end{array}$ & 0 & 0 & 280 & 82.4 & 60 & 17.6 \\
\hline 22 & $\begin{array}{l}\text { What language(s) do you speak at } \\
\text { home? }\end{array}$ & 170 & 50 & 40 & 11.8 & 130 & 38.2 \\
\hline 23 & $\begin{array}{l}\text { What language do you use in } \\
\text { office? }\end{array}$ & 0 & 0 & 300 & 88.2 & 40 & 11.8 \\
\hline 24 & $\begin{array}{l}\text { What language do you use at your } \\
\text { work place? }\end{array}$ & 50 & 27.7 & 240 & 67.6 & 50 & 14.7 \\
\hline 25 & $\begin{array}{l}\text { What language do you use at } \\
\text { market? }\end{array}$ & 130 & 38.2 & 110 & 32.4 & 100 & 29.4 \\
\hline 26 & $\begin{array}{l}\text { What language you use in the } \\
\text { religious place? }\end{array}$ & 0 & 0 & 290 & 85.3 & 50 & 14.7 \\
\hline
\end{tabular}

The second objective of this research is to identify the use of Guragigna language in family, market, friendship, religion, employment and education domains. When speakers use two languages they will not use both languages in all circumstances, but will choose one over the other according to participants, situation, content of discourse and function of interaction (Grosjean, 1982; as cited in Hohental, 1998).To address this objective around ten-items are developed in Part-3 of the questionnaire. The findings of this part of the questionnaire is presented below

This part of the questionnaire contains three items to identify the form of Guragina the participants commonly use: Speaking, writing and reading.

While the majority of the respondents (50\%) disclosed that they use Amharic for oral communication in the society, $41.2 \%$ of them replied they use Amharic and Guragina. Only $8.8 \%$ of the respondents reported that they use Guragina for oral communication in the society. This shows that the community is bilingual and there is language shift. Language whose speakers are highly bilingual in a dominant language is classified as endangered and its speakers are likely to shift to the dominant language.

As can be seen in the table above, $100 \%$ of the respondents said that the respondents choose Amharic as a language of writing. Similarly, $100 \%$ of the participants choose Amharic for reading. None of the respondents chose Guragina as a language of writing and reading. Failure to use the language for writing and reading seems to be due to limited social and economic opportunity that requires the use of these skills.

The findings of item-18 and 19 indicates that the language is vulnerable to be endangered.

Moreover in this section, the participants were asked to choose the language they use in a given domain. Concerning the use of Guragina in different domains, seven items were set and the findings are presented here.

As can be seen in the above table, in courts $94.1 \%$ of the participants use Amharic and 5.9 of them use a mix of the two. None of them use Guragina alone in the court.

Similarly, in health sectors $82.4 \%$ of the respondents use Amharic and17.6\% of them switch from Amharic to Guragina or vice-versa. None of them use Guragina alone in health sector.

However, $50 \%$ of the participants said they use Guragina at home $38.2 \%$ being a mix of Guragina and Amharic. The other $11.8 \%$ use Amharic at home. The finding indicates that there is also a tendency of language shift at home, and Guragina is not dominant even at home.

In offices, $88.2 \%$ of them use Amharic, and none of them use Guraginaalone. $11.8 \%$ of them use a mix of the two. In work places $27.7 \%$ of the participants use Guragina and $14.7 \%$ of them make a shift from Amharic to Guragina or vice-versa, and $67.7 \%$ of them use Amharic.

In market, $38.2 \%$ of the informants use Guragina where as $32.4 \%$ of them use Amharic. 29.4\%of them use both. In 
market where most of the people are indigenous, Amharic is still competing with Guragina and there is a shift.

In religious places, $85.3 \%$ of the respondents use Amharic and $14.7 \%$ of them mix the two. Nobody uses Guragina alone in such places.

Generally, it can be inferred that Amharic is dominantly used for speaking, writing and reading in Gurage community, but Guragina if used it is restricted to oral communication. On the other hand, Guragina is mainly used at home and market domains. Amharic is the dominant language in the court, office and religious places with some shift from Amharic to Guragina or vice-versa. If a Guragina is used in other domain other than home, it is often mixed with Amharic.

\section{The Status of Guragina Language across Generations}

Table4:-Language use across generations

In order to assess the status of Guragina language across generations, four items were included in the questionnaire. Item-27 was devised to identify if the participants parents/ grandparents speak Guragina well. The majority, $79.4 \%$, of the participants said Yes, and only $4.9 \%$ of them replied No. This indicates that Guragina is parental/grandparental language.

With regards to item-28 that intends to identify whether the participants speak Guragina well $70.6 \%$ of them said Yes, and $20.6 \%$ of them said No. The data clearly shows that some part of the people cannot speak Guragina.

As can be seen in the table above, $55.9 \%$ of the participants reported that children or young generation do not speak Guragina and $38.2 \%$ of them were Uncertain. It is only $2.9 \%$ of the respondents that said children speak Guragina.

This implies that the language is endangered.

\begin{tabular}{|l|l|l|l|l|l|l|l|}
\hline S.n & Item & \multicolumn{2}{l|}{ Yes } & No & \multicolumn{2}{l|}{ Uncertain } \\
\cline { 3 - 8 } & & F & $\%$ & F & $\%$ & F & $\%$ \\
\hline 27 & $\begin{array}{l}\text { Can your parents/grandparents speak } \\
\text { Guragina well? }\end{array}$ & 325 & 95.1 & 15 & 4.9 & - & - \\
\hline 28 & $\begin{array}{l}\text { Can you speak Guragina well? generation } \\
29\end{array}$ & $\begin{array}{l}\text { Are children/ young } 10 \\
\text { speakGuragigna well? }\end{array}$ & 2.9 & 190 & 55.9 & 130 & 38.2 \\
\hline 30 & $\begin{array}{l}\text { Do you believe that your Guragigna skill } \\
\text { strengthened time to time? }\end{array}$ & 110 & 32.4 & 220 & 64.7 & 10 & 2.9 \\
\hline
\end{tabular}

A language is said to be endangered when the children are not learning to speak the language although they may understand it a little.

Similarly, $64.7 \%$ of the informants reported that they do not believe that their Guragigna skill is being strengthened time to time. It is only $32.4 \%$ of the respondents that reported Yes indicating their Guragina is improving from time to time.

From the findings of this part of the questionnaire, we can understand that the use of Guragina is declining from parental/grandparental generation to the young generation. It is commonly spoken by older speakers.

The Status of Guragina Language for Various Functions

Table 5: Guragina Language for Various Functions

\begin{tabular}{|l|l|l|l|l|l|l|l|}
\hline \multirow{2}{*}{ S.n } & \multirow{2}{*}{ Item } & \multicolumn{2}{l|}{$\begin{array}{l}\text { I would not } \\
\text { participate }\end{array}$} & \multicolumn{2}{l|}{ I would participate } & \multicolumn{2}{l|}{$\begin{array}{l}\text { I have } \\
\text { participate }\end{array}$} \\
\cline { 3 - 8 } & & F & \% & F & \% & F & \% \\
\hline 31 & Reading Guragiga newspapers & 280 & 82.4 & 40 & 11.8 & 20 & 5.9 \\
\hline 32 & Watching Guragina TV & 230 & 67.6 & 60 & 17.6 & 50 & 14.7 \\
\hline 33 & Listening to radio programs & 290 & 85.3 & 0 & 0 & 40 & 11.8 \\
\hline 34 & Listening to music & 60 & 17.6 & 230 & 67.6 & 50 & 14.7 \\
\hline 35 & Viewing Guragina language websites & 250 & 73.5 & 90 & 26.5 & 0 & 0 \\
\hline 36 & Having organizied Recording Guragina & 210 & 61.8 & 70 & 20.6 & 60 & 17.6 \\
\hline
\end{tabular}


In order to achieve the third specific objective set, seven items were included as can be seen in table-5 above. With regards item-31 the respondents replied that they would not participate in reading Guraginanews papers. However, $11.8 \%$ of them said they would participate in reading Guraginanews paper. Only 5.9 of them have said that they have experience of reading. This implies that there is little or no access of Guragina newspaper.

With regards watching TV, the majority, $67.6 \%$ of them indicated they would not participate in this language activity. $14.7 \%$ of them replied they have the experience of watching TV. This small number of opportunities could be watching TV shows translated to Guragina.

The participants, $85.3 \%$ of them, reported that they would not participate in listening to radio programs. Only 11.8 $\%$ of them said they participate in listening to radio. This little opportunity could be that of translated listening programs.

The participants, $67.6 \%$, showed high frequency of listening to Guraginamusics. In this regard Guragina is of good status since Guragina has some singers that make interesting musics. The finding shows that Music is an important function of Guragina that contribute to maintaining and expressing culture and identity of Gurage.

The data in item-35 indicates that Guragina is not a language of website, $73.5 \%$ of the respondents stated they have no such experience.

Similarly, in item-35 we can see that high proportion of the respondents stated that they would not participate in recording and documenting the language, $61.8 \%$. A language which is not widely documented and recorded is viable to endangerment.

The findings of this part of the questionnaire indicated that Guragina is of a low status language with regards to its function in the newspaper and media. That means it has low access to be read and listened by a wider community. Similarly, it has low status of its documentations. It is not widely used in writing.

Frequency/Status of Guragina Language use with Others

Table 6:The frequency of respondents Guragina language use with other people

\begin{tabular}{|l|l|l|l|l|l|l|l|l|l|l|l|}
\hline \multirow{2}{*}{ s.n } & $\begin{array}{l}\text { Item } \\
\text { Who do you speak }\end{array}$ & \multicolumn{2}{l}{ Never } & \multicolumn{2}{l|}{ Rarely } & \multicolumn{2}{l|}{ Sometimes } & \multicolumn{2}{l|}{ Often } & \multicolumn{2}{l|}{ Always } \\
\cline { 2 - 13 } & Guragina? & F & $\%$ & F & $\%$ & F & $\%$ & F & $\%$ & F & $\%$ \\
\hline 37 & Spouse or partner & 35 & 10.3 & 20 & 5.9 & 110 & 31.1 & 90 & 26.8 & 85 & 25.3 \\
\hline 38 & Children & 180 & 52.9 & 40 & 11.8 & 80 & 23.5 & 0 & 0 & 40 & 11.8 \\
\hline 39 & Parent(s) & 10 & 2.9 & 20 & 5.9 & 40 & 11.8 & 90 & 26.5 & 180 & 52.9 \\
\hline 40 & Grandparent(s) & 10 & 2.9 & 20 & 5.9 & 20 & 5.9 & 30 & 8.8 & 260 & 76.5 \\
\hline 41 & Sibling(s) & 20 & 5.9 & 50 & 14.7 & 170 & 50 & 10 & 2.9 & 90 & 26.5 \\
\hline 42 & Other family members & 10 & 2.9 & 120 & 35.3 & 170 & 50 & 20 & 5.9 & 20 & 5.9 \\
\hline 43 & Co-workers & & & 120 & 35.3 & 150 & 44.1 & 50 & 14.7 & 20 & 5.9 \\
\hline 44 & Non-related & 20 & 5.9 & 70 & 20.6 & 190 & 55.9 & 30 & 8.8 & 30 & 8.8 \\
\hline 45 & Community members & 10 & 5.9 & 50 & 29.4 & 70 & 44.1 & 10 & 5.9 & 15 & 8.8 \\
\hline
\end{tabular}

In order to find out the status of Guragina language use with others and identify with whom the participants use Guragina most frequently nine items were designed.

In the table above, it can be seen that most (31.5\%) of the respondents use Guraginasometimes with their partner. $26.8 \%$ of them Often and $25.3 \%$ speak Guraginaalways.

With children $52.9 \%$ never use Guragina. 26.5\% use often and $52.9 \%$ use always with parents. This confirms that Guragina is widely used by parental generation.

The majority of respondents reported always with siblings (26.5\%), rarely with other family members (35.3\%), sometimes with co-workers $(44.1 \%)$, sometimeswith non-related $(55.9 \%)$, sometimes with community members $(44.1 \%)$. 
The findings indicate that the majority of the community rarely uses Guragina with children and with family members, sometimes with co-workers, non-related and community members.

Teaching Guragina in Schools as Subject

Table 7:-Participants Attitude towards incorporating Guragina in school curriculum

\begin{tabular}{|c|c|c|c|c|c|c|c|c|c|c|c|}
\hline \multirow[t]{2}{*}{ S.n } & \multirow[t]{2}{*}{ Item } & \multicolumn{2}{|c|}{$\begin{array}{l}\text { Strongly } \\
\text { disagree }\end{array}$} & \multicolumn{2}{|c|}{ Disagree } & \multicolumn{2}{|c|}{ Uncertain } & \multicolumn{2}{|c|}{ Agree } & \multicolumn{2}{|c|}{ Strongly agree } \\
\hline & & $F$ & $\%$ & $\mathrm{~F}$ & $\%$ & $F$ & $\%$ & $\mathrm{~F}$ & $\%$ & $F$ & $\%$ \\
\hline 46 & $\begin{array}{l}\text { Guragina should be taught in } \\
\text { school }\end{array}$ & 20 & 5.9 & 22 & 6.6 & 6 & 5.2 & 60 & 17.6 & 230 & 64.7 \\
\hline 47 & $\begin{array}{l}\text { It is impossible to teach } \\
\text { Guragina at school because of } \\
\text { its dialect difference }\end{array}$ & 130 & 38.2 & 50 & 14.7 & 100 & 29.4 & 20 & 5.9 & 40 & 11.8 \\
\hline 48 & $\begin{array}{l}\text { It is right for people not to learn } \\
\text { Guragina . }\end{array}$ & 130 & 38.2 & 150 & 44.1 & 15 & 4.4 & 15 & 4.4 & 30 & 11.8 \\
\hline 49 & $\begin{array}{l}\text { Including Guragina in the } \\
\text { curriculum is promoting culture } \\
\text { and identity of the people }\end{array}$ & 40 & 11.8 & 30 & 8.8 & 7 & 2.2 & 120 & 35.3 & 143 & 42.1 \\
\hline 50 & $\begin{array}{l}\text { Supporting to embrance the } \\
\text { language in curriculums for } \\
\text { schools }\end{array}$ & 7 & 2.2 & 17 & 5.3 & 53 & 14.7 & 23 & 6.6 & 240 & 70.6 \\
\hline
\end{tabular}

In order to address the third specific objective that states the feasibility of including Guragina language in the school curriculum. The Attitude questionnaire includes the items for identifying the respondents' belief to incorporate Guragina in a school curriculum. The findings of this part of the questionnaire are presented below.

With regards to item 46 , that intends to identify whether Guragina should be taught in schools $64.7 \%$ of the respondents Strongly Agreed and $17.6 \%$ of them Agreed.

While the home and the community remain the most crucial domains for language use and transmission, schools can play an important role as an additional place where languages are used and shown to be valued.

Item-47 was devised to find out whether it is impossible to teach Guragina at school because of its dialect difference. While $38.2 \%$ of the respondents replied Strongly Disagree, $14.7 \%$ of them reported Disagree to this item. $11.8 \%$ and $5.9 \%$ of the participants replied Strongly Agree and Agree respectively indicated that dialect difference could be a challenge to include the language in the curriculum. However, the response of the majority of respondents implies that dialect difference is not the challenge.

Regarding item-48, the majority (44.1\%) of the informants said Disagree on this item which states it is right for people not to learn Guragina , and $38.2 \%$ of them replied that they Strongly Disagree to this item.

Item-49 was designed to point out participants' opinion whether including Guragina in the curriculum promotes culture and identity of the people. The majority, $42.1 \%$, of the participants said Strongly Agree and $35.3 \%$ of them reported Agree to this item.

This indicates that the place of Guragina in the curriculum is believed to have a great role in promoting culture and maintaining identity of Gurage people.

\section{Findings from Interview}

Regarding participants' attitude towards Guragina use and attitude, it is found that Guragina is important to build a strong Gurage identity, to preserve and develop the language, to justify a common origin, to facilitate intergroup communication, to achieve good governance and to develop economy.

The domains in which Guragina can be used, the existing possibilities and the potential risks in using Guragina have 
also been addressed. Many participants indicated that they would like to see Guragina used in all domains, such as education, administration and media. Some others, however, limit the common Guragina use to mass media and/or education. On the other hand, some of the respondents reject a common Guragina use in administration. A common Guragina use in administration is not recommended because Gurage Zone is inhabited by Guragina speakers and non-Guragina speakers, such as Qabena and Libido who may not understand the common Guragina. This finding is consistent with Fekede's (2015).

The key informants explained the existing practices in courts. They reported that courts use interpreters. The interpretation is both to the clients and judges as there are judges who do not understand Guragina and clients who do not understand Amharic. In cases where judges understand Guragina clients may use Guragina but the judges do not use Guragina to avoid bias. The key informants suggest the use of Guragina in courts in the future. Many of them also think that Guragina should be used in courts of each Gurage districts. They argue that there should not be any misunderstanding because of language used. With regards the use of Guragina in courts Fekede (2015) cites his informant, Weldegebriel, a court scenario where a client was wrongly judged because of misinterpretation as follows:

"Yesterday, I went to a court room and when they told me the problem they faced due to language interpreter is a pity. A woman accused of her husband for not supplying her with basic needs, but the interpreter explained the issue to the court differently as if she wanted a divorce. The next time she comes to the court, the woman found herself divorced. She then began to cry and shout that she has never asked for a divorce but for supply of food stuffs".

To summarize the findings from interview, Gurage people have positive attitude towards their language. They believe that Guragina is important to build a strong Gurage identity, to preserve and develop the language and to justify a common origin. However, their responses show that the use of Guragina in different domains is limited.

\section{Findings of Focus Group Discussion}

The discussants in the focus group discussion reported some general attributes towards Gurage. Some Gurage people were ashamed of their identity; they failed to use their language.Gurage people are courteous; they use Amharic if there are non-Guragina speakersas interlocutors. Some Gurage people hide themselves by not speaking Guragina. In the past, Gurage people were mocked by others because of theirlanguage.

Here the attributes show that an individual or a group is not considered Gurage if he/she failed to speak his/her language either for purpose of accommodating others, example, Amharic speakers or because he is ashamed of using his own language, Guragina.

Some of the respondents reported the following concerning attitude towards Guragina.

1. Farmers mix Amharic, and even English word that they hear them from cadres, with Guragina.

2. In towns, people mix languages.

3. The new generation uses Guramayle 'a mixed language.

Generally, the participants expressed that Guragina is a low status language since it is not commonly used in different domains. Moreover, they expressed that children are not, generally, speaking the language, those who use the language is mixing it with Amharic. This indicates that there is language shift and there is low intergenerational language transmission.

\section{Discussion:-}

Few studies have examined how social psychological variables (e.g attitudes, identities, etc) affect linguistic behaviour amongst members of the Gurage communities. The present study examines social psychological and language data collected from members of the communities.

One of the specific objectives of this research was to investigate the attitude Gurage people possess towards Guragina. The participants showed a positive attitude towards Guragina for its symbolic value in promoting culture and identity. This is consistent with Fekede's (2015) finding that Gurage people value their language.

In order to understand the social psychological processes underlying the complexities of language and identity phenomena, Giles and his colleagues proposed a theory of "Ethno-linguistic identity". It should be noted that 
empirical testing of this theory suggests that language use and identity are related reciprocally: language use influences the formation of group identity, and group identity influences patterns of language attitudes and usage (see Giles \&Coupland, 1991; Sachdev\&Bourhis, 1990). The scholars further highlight that working to strengthen a language requires a detailed understanding of that language on its own terms, its history, its status, the attitude of the community, etc.

The second specific objective of this study was to identify whether the participants use Guragina in different domains of home, market, health centre, court, workplaces and so on. The finding indicated that Guragina is mainly used at home and market domains. This finding is also consistent with Fekede's result that the respondents rarely use Guragina except home and market domains.

Domains analysis are included in this study because domains and language attitudes are interrelated. According to Hohental (1998), attitudes, which develop in a society during a course of time, can determine the domains in which a particular language is used in a society, and therefore determine the place a language holds in a society. When speakers use twolanguages, they will not use both languages in all circumstances, but will choose one over the other according to participants, situation, content of discourse and function of interaction (Grosjean, 1982; as cited in Hohental, 1998).

Due to the socio-economic interest,Gurage parents seem to allow the use of Amharic language in the home, which led to code mixing between Amharic and Guragigna language. This affected the need to converse in the mother tongue.

The fact that there is no school syllabus that requires Guragigna fluency for the primary school and secondary school years of a student, it is not surprising that if one goes to a Gurage household, it is common that the young children speak and are spoken to in the Amharic language.

Fewer and fewer speakers of the language speak Guragigna language to their children at home. Amharic language has taken over and became the predominant language of communication within the Gurage community. The fact that Amharic language becomes the dominant language is not only evident in urban areas but as well in remote Gurage villages in which a mixture of Amharic and Guragigna is evident.

The availability of Guragigna language in the media, such as in the local newspapers and radio seems to be inapplicable.

Moreover, parents seem to be reluctant to speak Guragigna language at home, but use Amharic language to communicate with their children. Home and parents especially, often the last important agent in preservation of any language (Antonini, 2002). Parent is model for children language learning and influence the likelihood of what language will the children adopt and learn (Bartram, 2006; Galindo \& Worthy, 2006).

Barrena et al. (2007) detail several reasons why communities struggle to revive their languages amongst are lack of status for the language or official support.

Educational, financial and political constraints imposed by federal and regional governments have severely impeded change, and reinforced the low status of Guragina language. Guragina as mother tongue medium of instruction is not available; is not a curriculum subject and not a medium.

The low status of the language is clearly reflected in the discrepancy between federal spending on 'official' language (ie. Amharic) and on Guragina language which earns no or little budget from the government.

\section{Summary, Conclusion Andrecommendations:-}

This chapter deals with the summary of the findings, conclusions, recommendations of alternative solutions for maintaining Guragina language based on the findings of the study.

The main objective of this study was to examine maintaining Guragina language with reference to attitude and status of the language in the community. In order to address this objective the following specific objectives were formulated: 
1. Investigate the attitudes the speakers possess towards Guragigna language

2. Identify the use of Guragigna Language in family, friendship, religion, employment and education domains

3. Find out the status of Guragigna language for various functions

4. Assess the feasibility of incorporating Guragigna as a subject at the elementary education curriculum.

In the course of answering these questions, descriptive survey method was employed. To this effect questionnaire, interview and classroom observation were utilized as instrument during data collection. Purposive sampling was employed to include the required language varieties. Simple random sampling was used to select the participants. Accordingly, the informants participated and provided dependable data. Furthermore, the obtained data were analyzed by employing frequency and percentage.

\section{Summary of Findings}

The major findings of the study are listed below.

1. The respondents value Guragina language and would like to see it developed and maintained, but the dominant role of Amharic seems to influence some of the participants to make language shift.

2. The participants showed a positive attitude towards Guragina for its symbolic value in promoting culture and identity. They believe that Guragina is a strong part of their identity and that connection with the language is critical for their wellbeing.

3. The respondents reported Strongly Agree, $64.7 \%$, and Agree, $29.4 \%$, respectivelyabout the importance oflearning and using Guragina.

4. The respondents are not satisfied with their current ability to speak the language; they make language shift to the use of Amharic.

5. The role of Guragina in writing and reading is limited. If used it is restricted to oral communication.

6. Guragina is mainly used at home and market domains. Amharic is the dominant language in the court, office and religious places with some shift from Amharic to Guragina or vice-versa.

7. The majority, $55.9 \%$, of the participants reported that children or young generation do not speak Guragina. The use of Guragina is declining from parental/grandparental generation to the young generation. It is commonly spoken by older speakers.

8. It is only $2.9 \%$ of the respondents that said children speak Guragina. This implies that the language is endangered. A language is said to be endangered when the children are not learning to speak the language although they may understand it a little.

9. High proportion of the respondents stated that they would not participate in recording and documenting the language, $61.8 \%$. A language which is not widely documented and recorded is viable to endangerment.

10. Guragina is of a low status language with regards to its function in the newspaper and media. The participants, $67.6 \%$, showed high frequency of listening to Guraginamusics. The finding shows that Music is an important function of Guragina that contribute to maintaining and expressing culture and identity of Gurage.

11. In using Guragina, with children the majority of respondents reported never, $52.9 \%, 26.5 \%$ use often and 52.9 $\%$ use always with parents. Similarly, the majority of respondents reported always with siblings (26.5\%), rarelywith other family members $(35.3 \%)$, sometimes with co-workers $(44.1 \%)$, sometimes with non-related (55.9\%), sometimes with community members $(44.1 \%)$.

12. While $38.2 \%$ of the respondents replied Strongly Disagree, $14.7 \%$ of them reported Disagree to the impossibility of teaching Guragina in school curriculum due to dialect difference. $11.8 \%$ and $5.9 \%$ of the participants replied Strongly Agree and Agree respectively indicated that dialect difference could be a challenge to include the language in the curriculum.

\section{Conclusions:-}

Based on the findings and discussions made in this study, the following conclusions were made.

1. Gurage people have positive attitude towards the language. They want to preserve and maintain the language; they want their language to be taught in school.

2. The language is susceptible to endangerment since intergenerational language transmission is weak; children generally are reluctant to speak Guragina, speaking Guragina is confined to home and market domains, and there is language shift in other domains.

3. Guragina is a low status language with low social and economic prestige; poor documentation.

\section{Recommendations}

On the basis of the findings and the conclusions drawn out of them, the following recommendations were made. 
1. Guragina language centre should be opened at Wolkite University for documentingand studying the language.

2. All levels of government should support the profile and prestige of Guragina language by allowing it to be used in a range of public functions such as legal situation, health situations, etc.

3. In short term, the regional and local governments should introduce Guragina language as a subject to be taught in schools using compartative analysis of Guragina language varieties, and in long term it should be used as medium of instruction by standardizing Guraginavarities.

4. The Zonal government should seek ways for using Guragina in local radios and other media.

5. Further research should be done on the extent of the dialectical differences exist among the varieties.

\section{References:-}

1. Allard, R. and Landry, R. (1986) "Subjective ethnolinguistic vitality viewed as a belief system." Journal of Multilingual and Multicultural Development, 7:1-12.

2. AFN (1990) Towards Linguistic Justice for First Nations. Ottawa: Assembly of First Nations Education Secretariat: Ottawa.

3. Barrena, A., Amorrortu, E., Ortega, A., Uranga, B., Izagirre, E., \&Idiazabal, I. (2007). Small languages and small language communities 56: Does the number of speakers of a language determine its fate? International Journal of the Sociology of Language, 186, 125-139.

4. Barsh, R.L. (1994) “Canada's Aboriginal Peoples: Social Integration or Disintegration?” The Canadian Journal of Native Studies, 14: 1-46.

5. Bell, L., Burton, D., Funk, A. and White, J (1995) “Aboriginal Education Program: Case Study.” B.C. School District No. 50 (Queen Charlotte).

6. Bernard, H. R. (1996). Language Preservation and Publishing. In N. H. Hornberger (Ed.), Indigenous Literacies in the Americas: Language planning from the bottom up (pp. 136-156). Berlin: Mouton de Gruyter.

7. Bourhis, R. Y., Giles, H. and Rosenthal, D. (1981) "Notes on the construction of a 'Subjective Vitality Questionnaire' for ethnolinguistic groups.” Journal of Multilingual and Multicultural Development, 2: 144-55.

8. Broadhead, J. (1995) GwaiiHaanas Transitions Study. Queen Charlotte Islands: Queen Charlotte Islands Museum Press.

9. Blair, H., Rice, S., Wood, V., \&Janvier, J. (2002). Daghida: Cold lake first nation works towards dene language revitalization. In B. Burnaby, \& J. A. Reyhner (Eds.), Indigenous languages across the community (pp. 89-98). Flagstaff, AZ: Northern Arizona University: Center for Excellence in Education.

10. Crystal, D. (2000). Language Death. Cambridge: University Press.

11. Clement, R. (1986) "Second Language Proficiency and Acculturation: An investigation of the effects of language status and individual characteristics.” Journal of Language and Social Psychology, 5: 271-290.

12. Comrey, A.L. (1973) A first Course in Factor Analysis. New York: Academic Press.

13. Cummins, J. (1986) "Empowering Minority Students." Harvard Educational Review, 56: 18-3.

14. Fekede, M.(2015). Intergroup Communication among the Gurage. A Study on Intelligibility, Interlingua Comprehension and Accommodation. Lap Lambert Publishing.

15. Giles, H., Leets, L. andCoupland, N. (1990) "Minority Language Group Status: a theoretical conspexus." Journal of Multilingual and Multicultural Development, 11: 37-56.

16. Lambert, W. (1977) "Effects of bilingualism on the individual." In Bilingualism: Psychological, Social and Educational Implications, edited by P. A. Hornby. New York: Academic Press. 